\title{
Residual Fertility in Childhood Cancer Survivors
}

\author{
Cesare Battaglia, Fulvia Mancini, Nicola Persico, Arianna Cianciosi, \\ Paolo Busacchi, Domenico de Aloysio
}

\author{
Department of Obstetrics and Gynecology, Alma Mater Studiorum-University of Bologna, Bologna, Italy \\ Correspondence: Cesare Battaglia \\ Department of Obstetrics and Gynecology, Alma Mater Studiorum-University of Bologna \\ Via Massarenti, 13 - 40138 Bologna, Italy \\ Tel: +39-051-6364437; Fax: +39-051-6364377; E-mail: cesare.battaglia@unibo.it
}

\begin{abstract}
During the past three decades, major improvements have been made in the treatment and cure of certain hematological malignancies, as well as solid tumors in young patients. As a result of improved survival, attention has been turned to the long-term physical and psychological sequelae of treatment. The loss of fertility in males and premature menopause in females are important and common longterm side effects of curative radio- and chemotherapy. The frequency of fertility failure varies with the type, dose, duration of radio- and chemotherapy, and age of patient. Currently, there are no good estimates of the magnitude of the risk involved in relation to these factors. However, the combination of hormonal values, pubertal staging and the ultrasonographic and Doppler analyses of the gonads may noninvasively study the subtle modification following anticancer therapies. This could help to find new insights on potential preventive acts before initiation of the anticancer therapy, and hopefully, the restoration of fertility after treatment.
\end{abstract}

Key words: Radiotherapy, chemotherapy, gonadal function, spermatogenesis, spermatid, testicular function, uterine function cryopreservation, radiation doses.

\section{INTRODUCTION}

Pediatric tumors differ greatly from adult cancers in terms of their origin, distribution and prognosis. Only $1 \%$ of all new cases in the United States affect children. However, malignancies are the principal cause of death among children aged 1 to 15 years. ${ }^{1}$ Acute lymphocyte leukemia (ALL), brain tumors and sarcoma are more frequent in children, whereas acute and chronic myeloid leukemia, chronic lymphoid leukemia and carcinomas occur mostly in adults. The distribution of tumors changes during childhood through adolescence: the most common tumors in children of $<5$ years are ALL (36\%), lymphoma (10\%), kidney (10\%) and brain tumors (13\%). Between age 5 and 9 years ALL slightly decreases (31\%), lymphoma $(16 \%)$ and brain tumors increase $(25 \%)$ and kidney tumors represent only 5\%. Between age 10 and 14 years ALL, lymphoma and brain tumors are $18 \%, 25 \%$ and $18 \%$, respectively, of all malignancies. Bone tumors become more frequent (11\%). ${ }^{1}$
In the past, childhood malignancies were rapidly and inevitably fatal. However, of the approximately 7,500 children under 15 years of age who are found to have cancer in the United States each year, some $80 \%$ (or nearly 6,000), can expect to be cured of their diseases. It has been estimated that the prevalence of childhood cancer survivors (15 to 45 years of age) in the United States will increase from 1 in 1000 persons in 1990, to 1 in 900 persons in 2000 and, possibly, as many as 1 in 250 persons in the year $2010 .^{2}$ This is primarily due to an improvement in the combinations of surgery, radiotherapy (RT), and intensive multi-agent chemotherapy (CT). ${ }^{3}$ However, cancer is not a single disease and hidden within these overall figures are substantial differences between cancers in terms of overall survival. For ALL, the most common malignancy, survival is around $73 \%$. For a few cancers, the survival rates are above 90\% (Hodgkin's disease, retinoblastoma, germ cell tumors). Unfortunately, less success has been achieved with other cancers (central nervous system tumors or neuroblastoma). ${ }^{4}$ With the improvement of survival, it has become more and more obvious the need to screen survivors of childhood cancer for late effects of cancer therapy, because almost half of these subjects are likely to have or to develop disabilities that alter quality of life.

The possibility of severe gonadal damage is one of the more frequent sequelae as both male and female gonads are sensitive, although in different ways, to the damage-induced both by $\mathrm{CT}$ and irradiation. While CT has prevalent lesive effect on the testes, irradiation is responsible for severe damage to both testicular and ovarian functions.

\section{CHEMO/RADIOTHERAPY AND GONADAL FUNCTION}

\section{Males}

Spermatogenesis is a process, beginning at puberty and continuing throughout adult life, whereby totipotential stem cell, i.e. spermatogonia undergo continual self-renewal and differentiation into mature spermatozoa. 
It had been suggested that CT-induced damage is proportional to the degree of gonadal activity during treatment and that prepubertal children with inactive gametogenesis should have a lower incidence of injury. ${ }^{5}$ However, increasing evidence suggests that although testicular quiescence confers some degree of protective effect, most prepubertal boys starting from midpuberty, show the classical features of gonadal damage. ${ }^{6,7}$ Age of treatment, therefore, does not represent an important variable and the degree of gonadal injuries mostly depends on the characteristics of the $\mathrm{CT}$ agents, the duration of treatment, and dosage of the drugs. ${ }^{8}$ However, as most treatments are delivered as multi-agents regimen with often synergistic toxicity, it can be difficult to determine the specific contribution of each individual agent.

Alkylating agents (procarbazine, mechlorethamine, cyclophosphamide, chlorambucil, busulfan, etc.) have been identified as gonadotoxic. ${ }^{9}$ By acting as inhibitors of DNA synthesis they damage, in particular, cells with rapid mitotic activity (germinal cells of the testicular tubules), leading to severe germinal aplasia and adulthood oligo-azoospermia. ${ }^{10}$

Cyclophosphamide and chlorambucil do have dose dependent effects, but are reversible in up to $70 \%$ of patients after therapy-free intervals of several years. ${ }^{6}$ On the contrary, in pubertal males treated with MOPP (mechloethamine, vincristine, prednisone and procarbazine) or COPP (cyclophosphamide, vincristine, prednisone and procarbazine) evaluated 1 to 2 years after completion of therapy, azoospermia is found in 80 to $100 \%$ of the cases. ${ }^{11}$ This effect is reversible in only about $20 \%$ of cases even 7 years after therapy. ${ }^{11}$ The percentage may increase with fewer MOPP cycles and may decrease with pelvic irradiation. With the ABVD (adriamycin, bleomycin, vinblastine and dacarbazine) combination that contains no alkylating agent nor procarbazine, the incidence of azoospermia appears to be lower (36\%) and the incidence of recovery higher than after MOPP $(100 \%) .{ }^{11}$ Alternate cycles of ABVD with cycles of MOPP, are likely to be less gonadotoxic. Fertility is preserved in approximately $50 \%$ of patients following three cycles of MOPP/ABVD, compared to almost universal azoospermia following six cycles of MOPP. ${ }^{11}$

To an even greater extent than its effect on spermatogenesis, the effects of MOPP on Leydig cell function appear to be agerelated. The MOPP therapy, prior to the onset of puberty, leads to a normal pubertal progression. Gynecomastia with low testosterone and increased LH is developed in patients treated during adolescence. Compensated Leydig cell failure (increased LH with low normal testosterone levels or exaggerated FSH and LH response to $\mathrm{GnRH}$ ) without gynecomastia is seen in adults. ${ }^{12}$ However, in some patients treated during childhood, as they face puberty, LH values are higher than normal with testosterone levels that are at the lowest limit of the normal range. It has been suggested that this state of slight insufficiency of testosterone release is responsible for reduced bone mineral density in adulthood. ${ }^{13}$

The testis is one of the most radiosensitive tissues with very low doses of radiation causing significant impairment of function. Damage can be caused during direct irradiation of the testis or, more commonly, from scattered radiation during treatment at adjacent tissues. The more immature cells are more radiosensitive with doses as low as $0.1 \mathrm{~Gy}$, causing morphological and quantitative changes to spermatogonia. Doses of 2 to $3 \mathrm{~Gy}$ result in overt damage to spermatocytes leading to a reduction in spermatid numbers. At doses of 4 to 6 Gy, numbers of spermatozoa are significantly decreased implying damage to spermatid. ${ }^{14}$ Recovery of spermatogenesis takes place from surviving stem cells (type A spermatogonia) and is dependent on the dose of radiation. Complete recovery, as indicated by a return to pre-irradiation sperm concentrations and germinal cell numbers, takes place within 9 to 18 months following $1 \mathrm{~Gy}$ or less, 30 months after 2 to $3 \mathrm{~Gy}$, and 5 years or more for doses higher than $4 \mathrm{~Gy} .{ }^{14}$

It has been suggested that fractionation of radiotherapy increases gonadal toxicity. ${ }^{15}$ Doses of 1.2 Gy may represent a threshold for permanent testicular damage. Testicular doses of less than 0.2 Gy had no significant effect on FSH levels or sperm counts, whilst doses between 0.2 and 0.7 Gy caused a transient dose-dependent increase in FSH and reduction in sperm count, with a return to normal values within 12 to 24 months. ${ }^{16}$

Leydig cells are more resistant to injury by irradiation, but a high dose (>20 Gy) direct to the testes provokes severe testicular damage that will be followed not only by sterility, but also by impaired testosterone secretion. ${ }^{17}$ Most of these boys will therefore, require replacement therapy with testosterone to permit normal pubertal development and sexual activity. ${ }^{17}$

\section{Investigation of Testicular Function}

The only direct way to assess spermatogenesis is by semen analysis. However, in young males it is not always possible, for various reasons such as ethics, religion or shame, to obtain a semen sample. Therefore, it is very important to find indirect, but reliable ways to assess the effect of CT and RT on gonadal function.

Pubertal staging provides indirect information about Leydig cell function and spermatogenesis. ${ }^{18}$ The development of normal secondary sexual characteristics implies intact Leydig cell function with normal steroidogenesis. A reduced testicular volume ( $<15 \mathrm{ml}$, using the Prader Orchidometer), suggests impaired spermatogenesis. ${ }^{18}$

Hormone analysis should include the basal value of FSH, LH and testosterone. In prepubertal children hormonal evaluation is not as useful since the hypothalamic-pituitary- 
testicular axis is silent. In postpubertal boys, elevated LH and reduced testosterone levels indicate Leydig cell dysfunction. Elevated FSH with normal testosterone levels indicate germ cell failure. $^{19}$

Ultrasonography of the testis provides information on tissue morphology (in a gray scale) and enables to calculate the testicular volume more accurately than with the Prader orchidometer (Fig. 1). The simultaneous addition of color Doppler provides informations on blood flow (in color). Recent reports demonstrated a direct correlation between FSH and testicular vascularization, and an inverse correlation between the testicular volume and the pulsatility index of the transmediastinal artery (TMA). ${ }^{20,21}$ Thus, in absence of a semen analysis, the combination of hormonal values, pubertal staging and ultrasound study of the testis may predict the testicular damage provoked by CT/RT.

It has been shown that children treated with higher doses of cyclophosphamide, procarbazine, and dacarbazine, present a more evident testicular damage as confirmed by significantly higher FSH levels, lower testicular volume, and more elevated TMA resistances (Fig. 2). ${ }^{22}$ As the seminiferous tubules represent approximately 80 to $85 \%$ of the testicular mass, a small testicular volume and elevated FSH may suggest a significant impairment of the seminiferous tubules with subsequent testicular fibrosis, damaged spermatogenesis, and inhibin deficiency. ${ }^{23}$ In a recent study, ${ }^{22}$ TMA resistances resulted in higher rates in patients treated with higher cytotoxic doses (Fig. 3). Since the testicular mediastinum is the entry site for the main testicular vessels and PI is used as a measure of blood flow impedance distal to the point of sampling, elevated PI values may express a low testicular vascularization. The authors speculated that in patients with childhood malignancies treated with CT/RT, the severely altered testicular structure could be associated with fibrotic processes and significant decrease of blood flow supply to the testes. ${ }^{22}$ In fact, these patients showed a high testicular texture score, which is known to be correlated with a low number of germinative tubules and an increased number of obliterated tubules,${ }^{24}$ and with a reduced sperm count. ${ }^{25}$

\section{Females}

Chemotherapy causes both early and late effects which limits the dose and schedule of exposure. The ovary is chemosensitive, but there are no data on threshold doses for ovarian dysfunction.

The number of primordial follicles reaches a peak around six months intrauterine life at approximately $7 \times 10^{6}$ follicles. There is an exponential decline in follicles throughout infancy to adulthood by atresia, with only approximately 400 being released as mature oocytes. When the number of remaining primordial follicles falls below one thousand, the menopause occurs. ${ }^{26}$

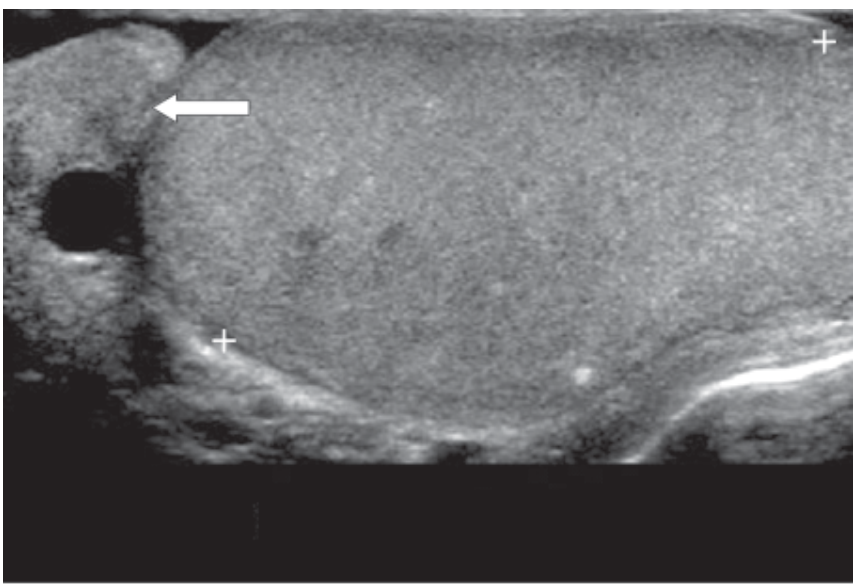

Fig. 1: Ultrasonographic representation of the didymis (comprised between the two crosses) and of the epididymis (arrow).

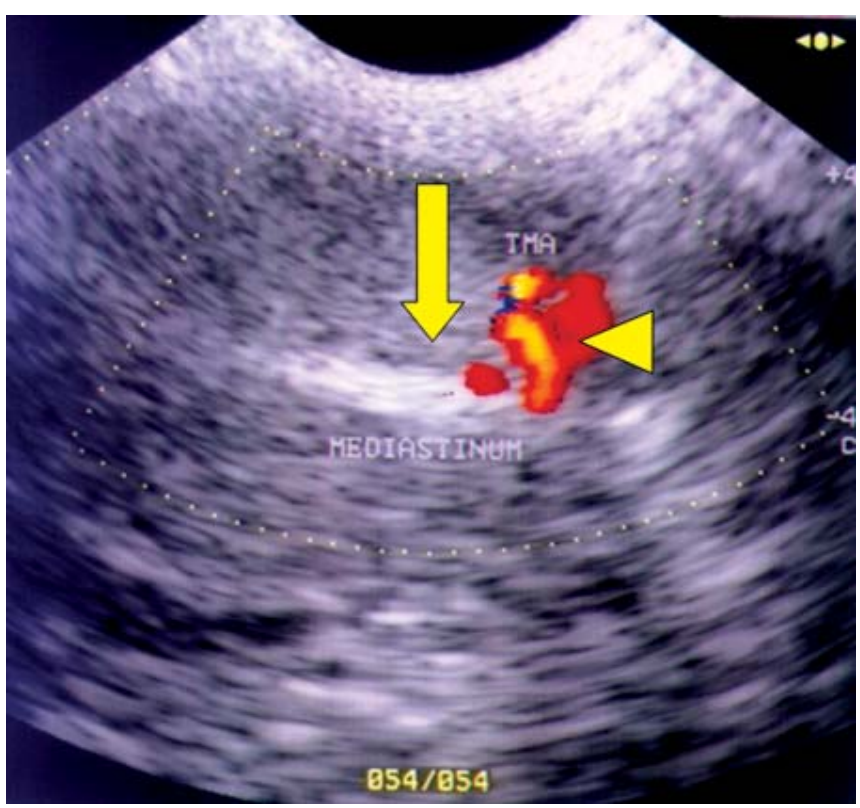

Fig. 2: Color flow image of the transmediastinal artery (TMA). The TMA is sampled in longitudinal plane at the level of the testicular mediastinum. $($ arrow $=$ testicular mediastinum; triangle $=\mathrm{TMA}$ )

There is a relationship between the age of menopause and childhood cancer survivors and the treatment to which they have been exposed. A review of 1,067 women who were more than 5 years on treatment for cancer, diagnosed during the teenage years, demonstrated a risk of menopause four times greater than controls during their early twenties. ${ }^{27}$

Although the morbidity is less than in males, single alkylating agents (cyclophosphamide, busulfan, Lphenylalanine mustard) (RR 9.2) and MOPP are the best described culprits. ${ }^{26}$

There is a trend toward intensification of treatment, particularly with childhood leukemia. Thus, the risk of gonadal 


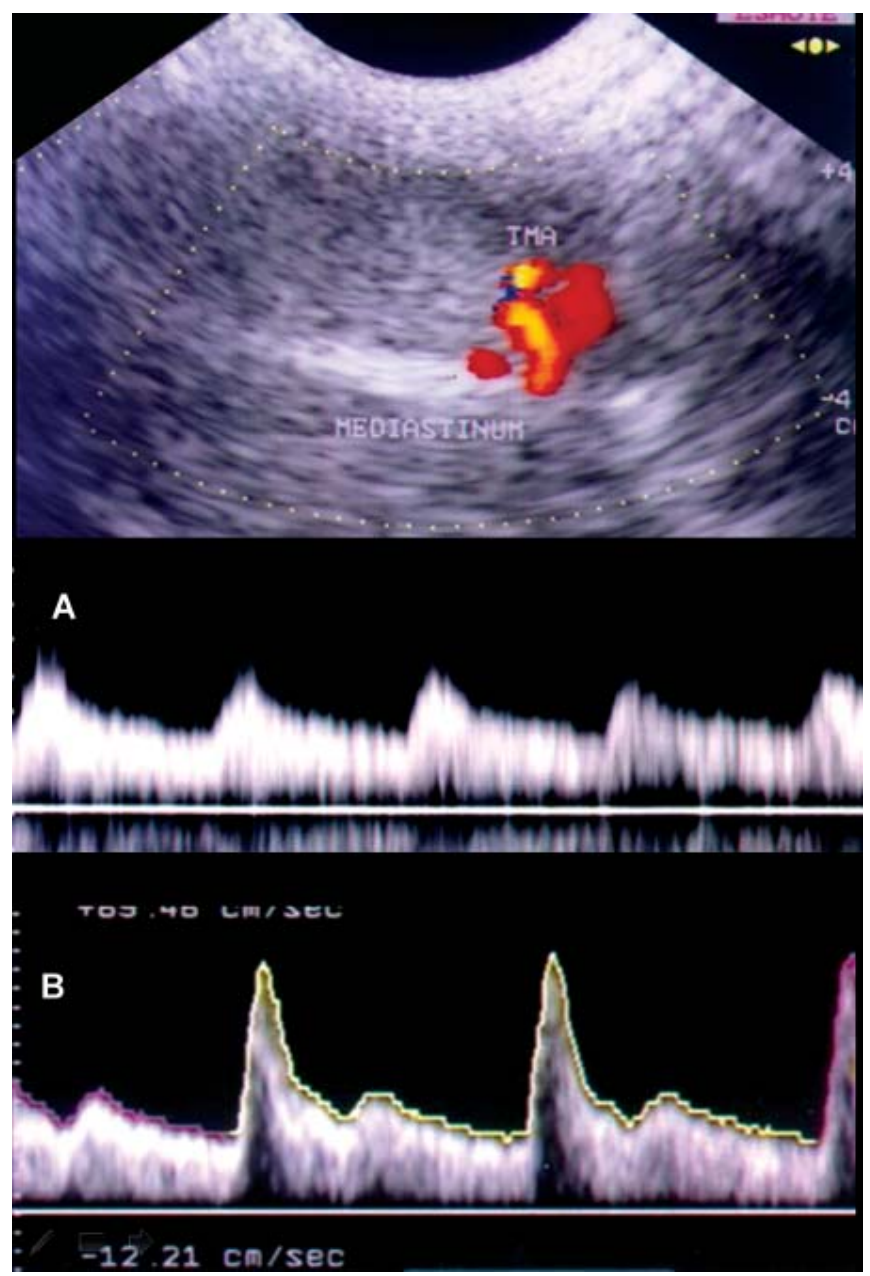

Fig. 3: Color Doppler analysis of the transmediastinal artery: (A) Normal vascularization in controls, $(B)$ increased resistances in male survivals of childhood malignancies

damage with these evolving regimens needs to be continuously evaluated. The majority of early reports of ovarian function in children treated with combination chemotherapy for ALL suggest that premature ovarian failure (POF) is uncommon. ${ }^{28}$ However, there have been reports of premature ovarian failure in women treated for ALL with more intensive regimens. ${ }^{29}$ Early reports of ovarian function following the treatment of Hodgkin's disease in childhood suggested that ovarian function was normal in all women studied. ${ }^{6}$ Children treated with cyclophosphamide (up to $200 \mathrm{mg} / \mathrm{kg}$ ) as conditioning for bone marrow transplant (BMT) had normal ovarian function in $95 \%$ of cases. However, higher doses (> $200 \mathrm{mg} / \mathrm{kg}$ ) result in POF. ${ }^{30}$

Chemotherapy does not appear to have any significant permanent adverse effect on uterine function. Successful pregnancy and healthy offspring are reported following treatment with multi-agent chemotherapy regimens. ${ }^{29,31}$

In the female, radiotherapy is responsible for dosedependent ovarian damage that may induce both sterility and impaired estradiol release. A radiation dose of 2,000 cGy below the diaphragm fractionated in 5 to 6 weeks provokes a complete depletion of the fixed pool of oocytes and ovarian failure occurs even when given in the prepubertal period. ${ }^{32}$ Even lower radiation doses such as those used for total body irradiation before BMT ( 800 to $1,000 \mathrm{cGy}$ ), may be followed by ovarian failure in young girls. Ovarian failure (high FSH levels and low estradiol values) may be reversible, but is always responsible for a reduction in the ovary pool resulting in premature menopause. ${ }^{33}$ Following a radiation insult, the size of the surviving population determines the "window" of opportunity for fertility and time until menopause. The depletion of primordial follicles that occurs at the time of the insult is related to the number present so that the younger the women at the time of treatment, the greater the number of follicles that survive and the later the onset of menopause. For 40 years old women, the permanent menopause is induced by $6 \mathrm{~Gy}$. In younger women and children, permanent sterility is produced with a total dose of $20 \mathrm{~Gy}$ over 6 weeks. ${ }^{34}$

An additional problem is that of cranial irradiation. A 4,000 to $5,000 \mathrm{cGy}$ irradiated on the hypothalamic-pituitary region result in delayed puberty and hypogonadism. ${ }^{35}$ Cranial irradiation at lower doses (1,800 to 2,400 cGy), such as used for ALL, may be associated with early puberty and subtle perturbations in growth hormone secretion. ${ }^{35}$ Young girls seem to be more sensitive to the cranial damage induced by irradiation, as suggested by the smaller pituitary dimension of girls treated at younger age. ${ }^{36}$

Recent data demonstrate that uterine function may be compromised following radiotherapy. Reduced uterine volume and decreased elasticity of uterine musculature, possibly as a consequence of impaired vascularization, are found in girls receiving pelvic, abdominal, and total body irradiation prepubertally. ${ }^{37}$ Although, successful pregnancy following radiotherapy is reported, the incidence of spontaneous miscarriage, premature delivery and intrauterine growth retardation is significantly increased. ${ }^{37}$ Women treated with total body irradiation who were given physiological sex steroid replacement therapy, have shown an increase in uterine volume and endometrial thickness. ${ }^{38}$

\section{Investigation of Ovarian/Uterine Function}

After anticancer therapy, the incidence of amenorrhea has been reported to vary between 40 and $68 \% .^{39,40}$ The frequency of ovarian failure seems to depend upon the type, dose and duration of the therapy ${ }^{41}$ and age of the patients with the eldest having a much higher incidence of permanent sterility than younger women. ${ }^{39,42}$ At the present moment, there are no definite estimates to calculate, in relation to these parameters, the magnitude of the risk for gonadal damage.

The assessment of the ovarian reserve (i.e. basal hormonal evaluation-FSH, estradiol, inhibin B; ovarian biopsy; ultrasonographic analysis of ovarian volume and small antral 
follicular count $)^{43}$ provides important information on the ovarian residual follicle pool but gives no data on spontaneous ovulation.

After ovulation, the corpus luteum forms from the dominant follicle and has a critical role in progesterone production. The rapid and massive production of progesterone is essential for regulating menses as well as for initiating and maintaining pregnancy. A mid-luteal progesterone concentration of $\geq 20$ $\mathrm{nmol} / \mathrm{L}$ is the most used indicator of an ovulatory cycle. With the advent of transvaginal probes and Doppler sonography, the corpus luteum can be now evaluated noninvasively. ${ }^{44}$ The corpus luteum appears as an ultrasonographic highly vascularized complex structure with peripheral flow easily identified on color Doppler analysis (Fig. 4). ${ }^{45}$

In females, although children treated for cancer may have an increased incidence of early menopause, ${ }^{42}$ several authors showed that a proportion of cancer survivors have regular menstrual cycle and normal endocrine profile. ${ }^{46,47}$ However, these patients may often experience an accelerated decline of fertility and risk involuntary childlessness which can seriously harm their self-esteem and quality of life. In the prepubertal child it is not possible to clinically or hormonally detect the potential extension of gonadal damage. However postpubertally, elevated gonadotropins levels and very low estradiol values are clear indicators of the ovarian failure and of the extensive follicular store depletion. ${ }^{26}$ An FSH rise in early follicular phase with maintained estradiol production has been recognized to be a feature of perimenopause and is detectable years before the definitive menopause. ${ }^{48,49}$ Nonetheless, the detection of a subtle dysfunction of the hypothalamus-pituitary-ovarian axis and the prediction of a premature menopause may be extremely difficult. Several studies observed that a significant proportion of cancer survivors who continued to have regular menses after CT/RT were at risk of developing premature menopause some years after treatment. ${ }^{47,50}$ Therefore, reassuring clinical information does not necessary imply that the ovaries escaped the damage. In fact, Byrne et $a l^{27}$ noted a $15 \%$ fertility deficit overall among survivors without a known reason for infertility and Larsen and coworkers ${ }^{51}$ affirmed that the "...ovarian age of female cancer survivors frequently is higher than their chronological age...As a consequence they may have a shortened reproductive span...". Ultrasonographic measurement of ovarian volume and antral follicle counts are possible indicators of ovarian aging. ${ }^{52,53}$

In a recent study, despite spontaneous pubertal development, regular menstrual cycles and normal early follicular FSH levels, patients who suffered from childhood malignancies and had been treated with chemo- and radiotherapy, evidenced a mean ovarian volume lower but not statistically significant from the controls. ${ }^{54}$ However, the cancer survivors showed increased resistances at level of intraovarian arteries (Fig. 5). From this, the authors hypothesized that the ovarian vascular

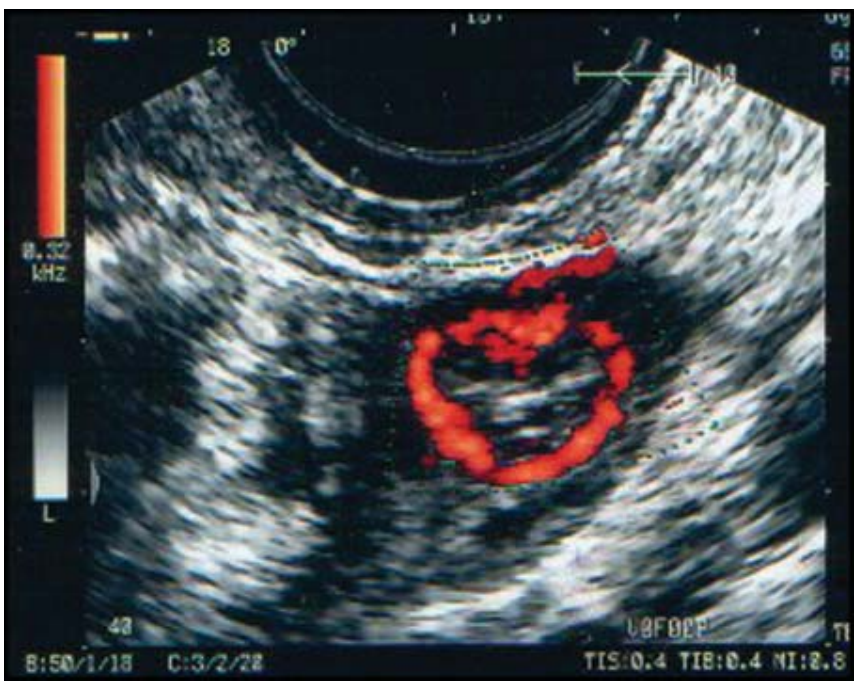

Fig. 4: Ultrasonographic representation of the corpus luteum which appears as a highly vascularized complex structure with color Doppler peripheral flow

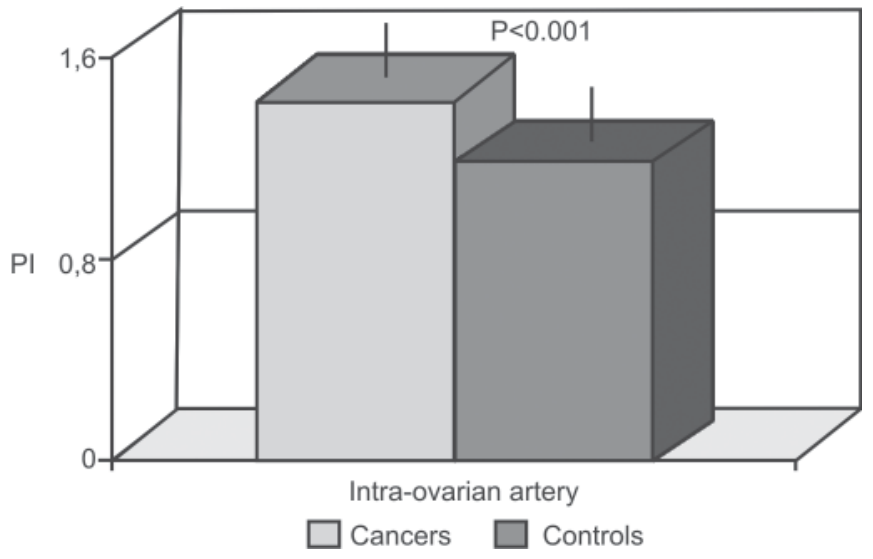

Fig. 5: Increased resistances at the level of intraovarian artery in female survivors of childhood malignancies compared to controls

deficit may represent the first alteration of ovarian function. ${ }^{54}$ Moreover, some of the patients showed ovulatory progesterone values and a highly vascularized corpus luteum; others, despite menstruating regularly, showed no sign indicating that ovulation had occurred (Fig. 6). These nonovulatory patients had low uterine volume and the resistances registered at level of uterine arteries were the highest. ${ }^{54}$ The authors noticed that the only difference between the ovulatory and the nonovulatory cancer survivors was that the time elapsed between the diagnosis of cancer and menarche was longer in ovulatory patients. Thus, the authors speculated that the resistance of prepubertal ovary is not total, that the utero-ovarian structures could be more vulnerable to $\mathrm{CT}$ in proximity of menarche and that, even in presence of normal menstrual cycles and early 


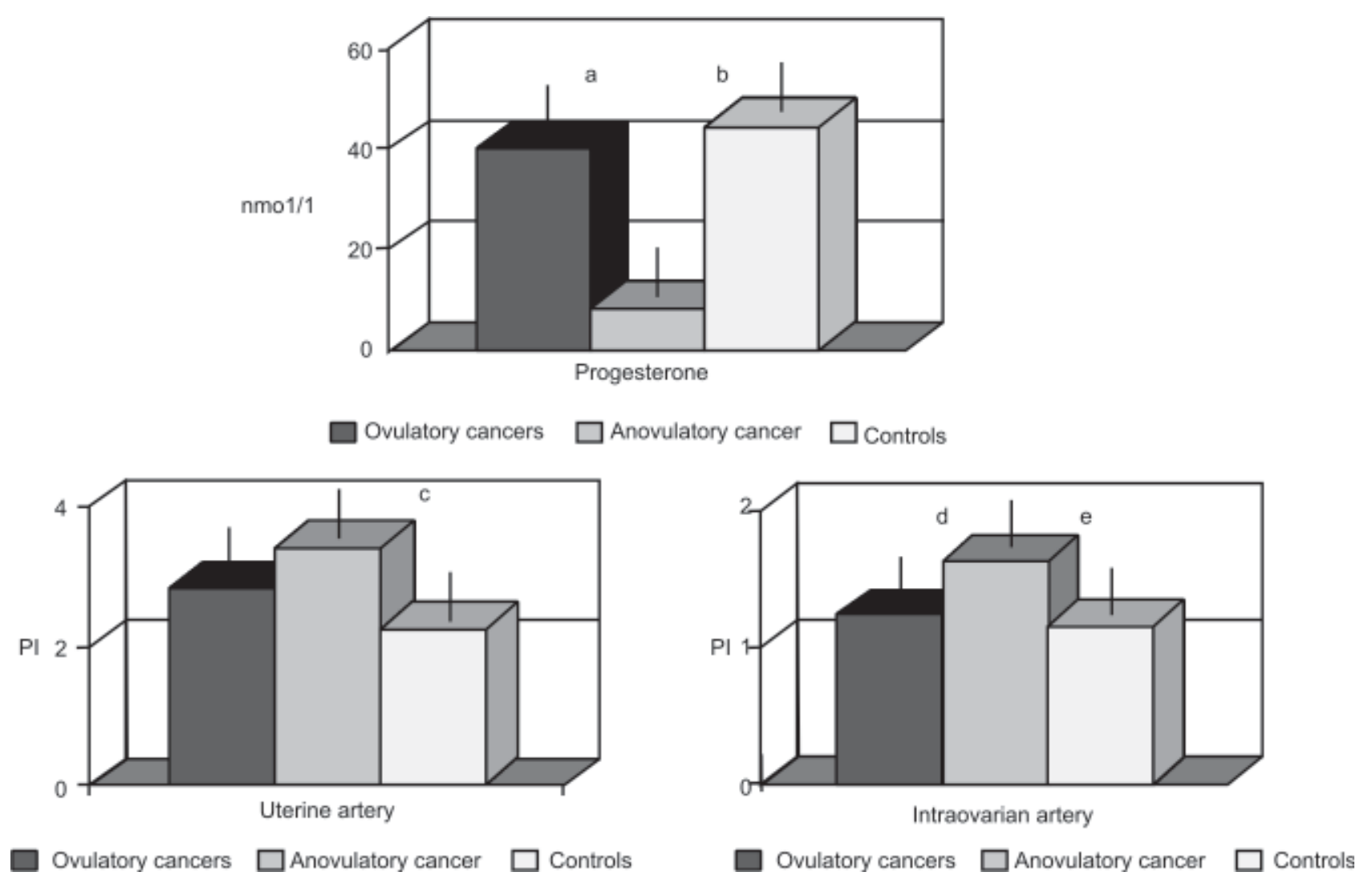

Fig. 6: Upper panel: progesterone circulating value in ovulatory and anovulatory female survivors of childhood malignancies compared to controls. Lower left panel: pulsatility index of uterine artery . Lower right panel: pulsatiliy index of intraovarian artery. Significance: ${ }^{\mathrm{a}} \mathrm{p}<0.0001$; ${ }^{b} p<0.0001 ;{ }^{c} p<0.001 ;{ }^{d} p=0.002 ;{ }^{e} p>0.001$

follicular FSH values, subtle ovarian vascular alterations may occur with increased risks of ovarian failure. ${ }^{54}$

\section{FERTILITY PRESERVATION}

The gonadal toxicities listed above, although not lifethreatening, are of serious concern to patients and their families. Advances in assisted reproduction and increasing interest in gamete extraction and maturation have focused on preserving gonadal tissue from children before sterilizing chemo- or radiotherapy, with the realistic expectation that future technologies will be able to utilize their immature gametes.

\section{Males}

Potential strategies for preservation of male fertility are dependent upon the sexual maturation of the patient. Spermatogenesis begins in puberty, although a number of immature spermatogenic cells are described in the prepubertal testis. Spermarche is a mid-pubertal event preceding the ability to produce an ejaculate, which occurs at median age of 13.4 (11.7 to 15.2) years when median testicular volume is $11.5 \mathrm{ml}$ (4.7 to $19.6 \mathrm{ml}) .{ }^{55}$

\section{Cryopreservation of Gametes}

It is the only established current clinical option for preservation of male infertility. Spermatozoa are obtained from the ejaculate by masturbation but may be also obtained using rectal electrostimulation techniques under anesthetics. ${ }^{56}$ When it is not possible to obtain an ejaculate, sperm can be retrieved by epididymal aspiration or testicular biopsy in sexually mature men. ${ }^{56}$ Not infrequently, sperm produced by cancer patients at the time of diagnosis is of poor quality ${ }^{56}$ However, with the introduction of intracytoplasmatic sperm injection (ICSI), the problem of low numbers and poor motility sperm has been partially bypassed. More recently, a small number of pregnancies have been achieved with ICSI using immature spermatids and secondary spermatocytes extracted from testicular tissue in men with spermatogenic arrest. ${ }^{57}$ 


\section{Experimental Strategies}

Studies have shown that the administration of GnRH agonists or antagonists to rats, either immediately or after a delay following treatment with $\mathrm{CT}$ or irradiation, restores the ability of spermatogonia to differentiate and resume normal spermatogenesis. However, studies in humans have failed any convincing evidence to clinical benefit. ${ }^{58}$ It is possible that endocrine manipulation to enhance recovery may be successful in patients in whom testicular damage is less severe and there is some preservation of spermatogonial stem cells.

For prepubertal boys, there are no options currently available to preserve fertility. Harvesting testicular tissue is an option still entirely experimental, although extremely attractive. ${ }^{59}$ Testicular tissue could be removed before the start of treatment and cryopreserved either as a segment of tissue or as isolated germ cells. After the treatment for cancer, the frozen tissue could be thawed and autografted to the testis, or the germ cells could be matured in vitro until they become sufficiently mature to achieve fertilization through ICSI.

Other experimental strategies include germ cell isolation and storage, germ cell enrichment, cryopreservation of spermatogonial stem cells, germ cell transplantation, germ cell in vitro maturation. ${ }^{19}$

\section{Females}

Reducing the radiation dose to the ovary by shielding or removing the ovaries from the field of radiation (oophoropexy) may preserve ovarian function. ${ }^{60}$ The ovaries are laparoscopically transposed to a position behind the uterus, away from the field of radiation to minimize exposure. ${ }^{60}$ However, even when ovarian function is preserved, the uterus may be damaged and the ability to achieve and carrying to term a pregnancy may be compromised.

The cryopreservation of embryos or oocytes are the only current available strategy for preservation of female fertility. However, embryo banking requires the patients to have a partner or to use sperm donor. Cryopreservation of oocytes is the alternative possibility for single women without a partner, but it is much less successful than embryo banking. ${ }^{19}$

\section{Experimental Strategies}

It has been hypothesized that inducing a prepubertal milieu during chemotherapy would decrease the risk of POF, ${ }^{19}$ and it has been demonstrated in rodents that $\mathrm{GnRH}$ analogs inhibit chemotherapy-induced ovarian follicular depletion, although this is still not an option in humans. ${ }^{19}$

Another experimental strategy is the prevention of follicle atresia by inhibiting apoptosis with ceramide. ${ }^{19}$ The treatment of mice oocytes with ceramide (and its derived sphingosine-Iphosphate) prevents apoptosis in vitro. In vivo, it confers a resistance to radiation-induced apoptosis in mice, with pregnancy rates of $100 \% .^{19}$

The only option potentially available for prepubertal children and the majority of young women is the cryopreservation of ovarian tissue. ${ }^{19}$ Ovarian tissue may be harvested by slicing the ovarian cortex which is rich in primordial follicles, or by cryopreserving the immature oocytes. Survival rates and viability post-thawing are good whether primordial follicles are stored as slices or in isolation. ${ }^{19}$ Moreover, with reimplantation, the return of ovarian activity has been achieved; however, no pregnancies have been reported. Immature oocytes show poor survival and increased rates of chromosomal abnormalities and spindle malformations. ${ }^{19}$

\section{CONCLUSIONS}

During the past three decades, major improvements have been made in the treatment and cure of certain hematological malignancies, as well as solid tumors in young patients. As a result of improved survival, attention has been turned to the long-term physical and psychological sequelae of treatment. The loss of fertility and premature menopause are unfortunately important and common long-term side effects of curative radioand chemotherapy. These facts have high impact on self-esteem and quality of life of these patients, because many are young and have expectations of a normal reproductive life. The prospect of ovarian failure in females and impaired fertility in males after antineoplastic therapy is a difficult topic for patients and clinicians to deal with, because of the lack of good prognostic information. The frequency of fertility failure varies with the type, dose, duration of radio- and chemotherapy, and age of patient. Currently, there are no good estimates of the magnitude of the risk involved in relation to these factors. It is, therefore, of outmost importance that research in this field is pursued and increased, in order to provide the appropriate information, consultation, potential preventive acts before initiation of the anticancer therapy, and hopefully, the restoration of fertility after treatment.

\section{REFERENCES}

1. Hann I, Vora A, Richards S, Hill F, Gibson B, Lilleyman J, Kinsey S, Mitchell C, Eden OB. Benefit of intensified treatment for all children with acute lymphoblastic leukemia: results from MRC UKALL XI and MRC ALL97 randomised trials. UK Medical Research Council's Working Party on Childhood Leukaemia. Leukemia 2000;14(3):356-63.

2. Sklar CA. Overview of the effects of cancer therapies: the nature, scale and breadth of the problem. Acta Paediatr (Suppl) 1999;88(433):1-4.

3. Landis SH, Murray T, Bolden S, Wingo PA. Cancer statistics, CA Cancer J Clin 1998;48:6-29. 
4. Gatta G, Capocaccia R, De Angelis R, Stiller C, Coebergh JW, EUROCARE Working Group. Cancer survival in European adolescents and young adults. Eur J Cancer 2003;39(18):260010.

5. Rivkees SA, Crawford JD. The relationship of gonadal activity and chemotherapy-induced gonadal damage. JAMA 1988;259(14):2123-5.

6. Mackie EJ, Radford M, Shalet SM. Gonadal function following chemotherapy for childhood Hodgkin's disease. Med Pediatr Oncol 1996;27(2):74-8.

7. Ben Arush MW, Solt I, Lightman A, Linn S, Kuten A. Male gonadal function in survivors of childhood Hodgkin and nonHodgkin lymphoma. Pediatr Hematol Oncol 2000;17(3):23952.

8. Cicognani A, Pasini A, Pession A, Pirazzoli P, Burnelli R, Barbieri E, Mazzanti L, Cacciari E. Gonadal function and pubertal development after treatment of a childhood malignancy. J Pediatr Endocrinol Metab 2003;16 (Suppl) 2:321-6.

9. Shafford EA, Kingston JE, Malpas JS, Plowman PN, Pritchard J, Savage MO, Eden OB. Testicular function following the treatment of Hodgkin's disease in childhood. Br J Cancer 1993;68(6):1199-1204.

10. Siimes MA, Rautonen J, Makipernaa A, Sipila I. Testicular function in adult males surviving childhood malignancy. Pediatr Hematol Oncol 1995;12(3):231-41.

11. Viviani S, Santoro A, Ragni G, Bonfante V, Bestetti O, Bonadonna G. Gonadal toxicity after combination chemotherapy for Hodgkin's disease. Comparative results of MOPP vs ABVD. Eur J Cancer Clin Oncol 1985;21(5):601-05.

12. Blatt J, Copeland DR, Bleyer WA. Late effects of childhood cancer and its treatment. In Philip A Pizzo, David G Poplack (Eds): Principles and Practice of Pediatric Oncology (3rd edn). Lippincott-Raven Publishers, Philadelphia 1997;1313.

13. Brennan BM, Rahim A, Adams JA, Eden OB, Shalet SM. Reduced bone mineral density in young adults following cure of acute lymphoblastic leukaemia in childhood. Br J Cancer 1999;79(1112):1859-63.

14. Howell SJ, Shalet SM. Effect of cancer therapy on pituitarytesticular axis. Int J Androl 2002;25(5):269-76.

15. Speiser B, Rubin P, Casarett G. Aspermia following lower truncal irradiation in Hodgkin's disease. Cancer 1973;32(3):692-8.

16. Kinsella TJ, Trivette G, Rowland J, Sorace R, Miller R, Fraass B, Steinberg SM, Glatstein E, Sherins RJ. Long-term follow-up of testicular function following radiation therapy for early-stage Hodgkin's disease. J Clin Oncol 1989;7(6):718-24.

17. Shalet SM, Didi M, Ogilvy-Stuart AL, Schulga J, Donaldson MD. Growth and endocrine function after bone marrow transplantation. Clin Endocrinol (Oxf) 1995;42(4):333-9.

18. Tanner JM, Whitehouse RH. Clinical longitudinal standards for height, weight, height velocity, weight velocity, and stages of puberty. Arch Dis Child 1976;51(3):170-9.

19. Thomson AB, Critchley HO, Kelnar CJ, Wallace WH. Late reproductive sequelae following treatment of childhood cancer and options for fertility preservation. Best Pract Res Clin Endocrinol Metab 2002;16(2):311-34.
20. Battaglia C, Giulini S, Regnani G, Di Girolamo R, Paganelli S Facchinetti F, Volpe A. Seminal plasma nitrite/nitrate and intratesticular Doppler flow in fertile and infertile subjects. Hum Reprod 2000;15:2554-8.

21. Battaglia C, Giulini S, Regnani G, Madgar I, Facchinetti F, Volpe A. Intratesticular Doppler flow, seminal plasma nitrites/nitrates, and nonobstructive sperm extraction from patients with obstructive and nonobstructive azoospermia. Fertil Steril 2001;75:1088-94.

22. Battaglia C, Pasini A, Mancini F, Burnelli R, Cicognani A, de Aloysio D. Role of intratesticular ultrasonographic and Doppler flow analyses in evaluating gonadal status in male survivors of childhood malignancy. Fertil Steril 2005;83(6):1867-70.

23. Schmiegelow M, Lassen S, Skovgaard Poulsen H, Schmiegelow K, Hertz H, Andersson AM, Skakkebaek NE, Muller J. Gonadal status in male survivors following childhood brain tumors. J Clin Endocrinol Metab 2001;86(6):2446-52.

24. Lenz S, Thomsen JK, Giwercman A, Hertel NT, Hertz J, Skakkebaek NE. Ultrasonic texture and volume of testicles in infertile men. Hum Reprod 1994;9(5):878-81.

25. Takihara H, Cosentino MJ, Sakatoku J, Cockett TK. Significance of testicular size measurements in andrology: correlation of testicular size with testicular function. J Urol 1987;137:416-9.

26. Bath LE, Wallace WH, Critchley HO. Late effects of the treatment of childhood cancer on the female reproductive system and the potential for fertility preservation. BJOG 2002;109(2):107-14.

27. Byrne J, Fears TR, Gail MH, Pee D, Connelly RR, Austin DF, Holmes GF, Holmes FF, Latourette HB, Meigs JW, et al. Early menopause in long-term survivors of cancer during adolescence. Am J Obstet Gynecol 1992;166(3):788-93.

28. Siris ES, Leventhal BG, Vaitukaitis JL. Effects of childhood leukemia and chemotherapy on puberty and reproductive function in girls. N Engl J Med 1976;294(21):1143-6.

29. Quigley C, Cowell C, Jimenez M, Burger H, Kirk J, Bergin M, Stevens M, Simpson J, Silink M. Normal or early development of puberty despite gonadal damage in children treated for acute lymphoblastic leukemia. N Engl J Med 1989; 20;321(3):143-51.

30. Sanders JE and The Seattle Marrow Transplant Team. The impact of marrow transplant preparative regimens on subsequent growth and development. Semin Hematol 1991;28(3):244-9.

31. Nicholson HS, Byrne J. Fertility and pregnancy after treatment for cancer during childhood or adolescence. Cancer 1993;71(10 Suppl):3392-9.

32. Shalet SM. Endocrine sequelae of cancer therapy. Eur J Endocrinol 1996;135(2):135-43.

33. Wallace WH, Shalet SM, Hendry JH, Morris-Jones PH, Gattamaneni HR. Ovarian failure following abdominal irradiation in childhood: the radiosensitivity of the human oocyte. Br J Radiol 1989;62(743):995-8

34. Wallace WH, Shalet SM, Crowne EC, Morris-Jones PH, Gattamaneni HR. Ovarian failure following abdominal irradiation in childhood: natural history and prognosis. Clin Oncol (R Coll Radiol) 1989;1(2):75-9.

35. Cicognani A, Cacciari E, Rosito P, Mancini AF, Carla G, Mandini M, Paolucci G. Longitudinal growth and final height in long- 
term survivors of childhood leukaemia. Eur J Pediatr 1994;153(10):726-30.

36. Cicognani A, Cacciari E, Carla G, Rosito P, Cau M, Mancini AF, Zucchini S, Vecchi V, Pirazzoli P, Paolucci G. Magnetic resonance imaging of the pituitary area in children treated for acute lymphoblastic leukemia with low-dose (18-Gy) cranial irradiation. Relationships to growth and growth hormone secretion. Am J Dis Child 1992;146(11):1343-8.

37. Critchley HO, Wallace WH, Shalet SM, Mamtora H, Higginson J, Anderson DC. Abdominal irradiation in childhood; the potential for pregnancy. Br J Obstet Gynaecol 1992;99(5):392-4.

38. Bath LE, Critchley HO, Chambers SE, Anderson RA, Kelnar CJ, Wallace WH. Ovarian and uterine characteristics after total body irradiation in childhood and adolescence: response to sex steroid replacement. Br J Obstet Gynaecol 1999;106(12):126572.

39. Meirow D. Reproduction post-chemotherapy in young cancer patients. Mol Cell Endocrinol 2000;169:123-31.

40. Brusamolino E, Lunghi F, Orlandi E, Astori C, Passamonti F, Barate C, Pagnucco G, Baio A, Franchini P, Lazzarino M, Bernasconi C.Treatment of early-stage Hodgkin's disease with four cycles of ABVD followed by adjuvant radio-therapy: analysis of efficacy and long-term toxicity. Haematologica 2000;85:1032-9.

41. Nicosia SV, Matus-Ridley M, Meadows AT. Gonadal effects of cancer therapy in girls. Cancer 1985;55:2364-72.

42. Chiarelli AM, Marrett LD, Darlington G. Early menopause and infertility in females after treatment for childhood cancer diagnosed in 1964-1988 in Ontario, Canada. Am J Epidemiol 1999;150:245-54.

43. Nikolau D, Templeton A. Early ovarian ageing: a hypothesis. Detection and clinical relevance. Hum Reprod 2003;18:1137-9.

44. Frates MC, Doubilet PM, Durfee SM, Di Salvo DN, Laing FC, Brown DL, Benson CB, Hill JA. Sonographic and Doppler characteristics of the corpus luteum: can they predict pregnancy outcome? J Ultrasound Med 2001;20:821-7.

45. Parsons AK. Imaging the human corpus luteum. J Ultrasound Med 2001;20:811-9.

46. Hudson MM, Greenwald C, Thompson E, Wilimas J, Marina N, Fairclough D, Kauffman W, Bozeman P, Mackert PW, Abromowitch M, et al. Efficacy and toxicity of multiagent chemotherapy and low-dose involved-field radiotherapy in children and adolescents with Hodgkin's disease. J Clin Oncol 1993;11:100-8.

47. Wallace WH, Shalet SM, Tetlow LJ, Morris-Jones PH. Ovarian function following the treatment of childhood acute lymphoblastic leukaemia. Med Pediatr Oncol 1993;21:333-9.

48. Sherman BM, West JH, Korenman SG. The menopausal transition: analysis of LH, FSH, estradiol, and progesterone concentrations during menstrual cycles of older women. J Clin Endocrinol Metab 1976;42:629-36.

49. Ahmed Ebbiary NA, Lenton EA, Cooke ID. Hypothalamicpituitary ageing: progressive increase in FSH and LH concentrations throughout the reproductive life in regularly menstruating women. Clin Endocrinol 1994;41:199-206.

50. Byrne J, Mulvihill JJ, Myers MH, Connelly RR, Naughton MD, Krauss MR, Steinhorn SC, Hassinger DD, Austin DF, Bragg K, et al. Effects of treatment on fertility in long-term survivors of childhood or adolescent cancer. N Engl J Med 1987;317:1315-21.

51. Larsen EC, Muller J, Rechnitzer C, Schmiegelow K, Andersen AN. Diminished ovarian reserve in female childhood cancer survivors with regular menstrual cycles and basal FSH < 10 IU/ 1. Hum Reprod 2003;18:417-22.

52. Pavlik EJ, DePriest PD, Gallion HH, Ueland FR, Reedy MB, Kryscio RJ, van Nagell JR Jr. Ovarian volume related to age. Gynecol Oncol 2000;77:410-2.

53. Scheffer GJ, Broekmans FJ, Dorland M, Habbema JD, Looman CW, Velde ER. Antral follicle counts by transvaginal ultrasonography are related to age in women with proven natural fertility. Fertil Steril 1999;72:845-51.

54. Battaglia C, Pasini A, Mancini F, Persico N, Burnelli R, Cicognani A, de Aloysio D. Utero-ovarian ultrasonographic and Doppler flow analyses in female childhood cancer survivors with regular menstruation and normal circulating follicle-stimulating hormone levels. Fertility and Sterility 2006;85(2):455-61.

55. Nielsen CT, Skakkebaek NE, Richardson DW, Darling JA, Hunter WM, Jorgensen M, Nielsen A, Ingerslev O, Keiding N, Muller $\mathrm{J}$. Onset of the release of spermatozoa (spermarche) in boys in relation to age, testicular growth, pubic hair, and height. J Clin Endocrinol Metab 1986;62(3):532-53.

56. Rosenlund B, Sjoblom P, Tornblom M, Hultling C, Hillensjo T. In-vitro fertilization and intracytoplasmic sperm injection in the treatment of infertility after testicular cancer. Hum Reprod 1998;13(2):414-41.

57. Bernabeu R, Cremades N, Takahashi K, Sousa M. Successful pregnancy after spermatid injection. Hum Reprod 1998;13(7):1898-1900.

58. Waxman JH, Ahmed R, Smith D, Wrigley PF, Gregory W, Shalet S, Crowther D, Rees LH, Besser GM, Malpas JS, et al. Failure to preserve fertility in patients with Hodgkin's disease. Cancer Chemother Pharmacol 1987;19(2):159-62.

59. Brinster RL, Zimmermann JW. Spermatogenesis following male germ-cell transplantation. Proc Natl Acad Sci USA 1994;91(24):11298-11302.

60. Thomas PR, Winstanly D, Peckham MJ, Austin DE, Murray MA, Jacobs HS. Reproductive and endocrine function in patients with Hodgkin's disease: effects of oophoropexy and irradiation. Br J Cancer 1976;33(2):226-31. 